TEMAS DE ACTUALIDAD Rev Chil Salud Pública 2013; Vol 17 (3): 224-233

\section{ALGUNAS IDEAS FUNDANTES EN EL SISTEMA DE SALUD CHILENO}

\author{
Some ideas at the foundation of the Chilean \\ Public Health System
}

\section{RESUMEN}

Una revisión de la historia de las formas de satisfacer la demanda, generar $y$ administrar hospitales en Chile se ha elaborado tomando como punto de partida la catástrofe que ha significado el terremoto del 27 de febrero de 2010. El recorrido se pasea desde algunas ideas caritativas del siglo XVI y culmina con las ideas de la actual administración liberal-conservadora, que asume después de 20 años de gobierno socialdemócrata. Se plantea la tesis de que la discusión acerca de cómo financiar, quién construye y quienes administran es menos relevante que la forma de hacer políticas de salud en Chile, incrementalista y desde la coyuntura, dada la preponderancia dela retórica politica por sobre la contundente evidencia sanitaria así como la falta de Integración social y en la puesta en escena del lucro en la respuesta social organizada en salud.

Palabras clave: Asistencia sanitaria, Sistema de Salud, determinantes sociales.

\begin{abstract}
An historical review of the ways to satisfied requests, generate and manage hospitals in Chile has been made taking the catastrophically earthquake of February 27, 2010. The route strolls from some of charitable ideas of XVI century and ends with those of actual liberal-conservative alliance, which is in control after twenty years of the social democratic one. A thesis of the relevance about how to finance, who build and who manage is less important than the way of made health policies in Chile, in increasable way and always from circumstances, been given the preponderance of the rbetorical politics over the massive sanitary evidence as much as the lack of social integration and the put on scene of profit as a organized answer on people's bealth.
\end{abstract}

Key words: Health assistance, Health system, Social determinants. 
INFRAESTRUCTURA ILUMINADA POR LA TRAGEDIA

Después del terremoto del 27 de febrero de 2010, quedó de manifiesto la cruda realidad de la red asistencial chilena, al constatarse que 25 de los hospitales de la red estatal habían resultado dañados. De ellos, 17 severamente, y otros ocho con daños estructurales. Se recibió entonces ayuda internacional: Hospitales de Campaña: Rusia, Italia, Brasil, Perú, Argentina, entre otros países, también enviaron hospicios de emergencia. Asimismo, las Fuerzas Armadas colaboraron con sus instalaciones sanitarias de guerra.

Como era esperable, esto situó rápidamente la discusión en materias de gobernanza sanitaria en definir plazos, metas y responsabilidades en cuanto a la oferta de infraestructura disponible para satisfacer la demanda por asistencia sanitaria de gran complejidad, esto es, fundamentalmente hospitales. Así se veía el panorama a principios de marzo de $2010^{1}$ como se muestra en la tabla 1.

El 11 de marzo de 2010 asumió el gobierno Sebastián Piñera, representante de la alianza liberal-gremialista, que nombró como ministro de Salud a Jaime Mañalich Muxi; quien antes de asumir, debió renunciar a su empleo de gerente médico de la Clínica Las Condes. ${ }^{2}$

Aunque es verdad que un inmenso terremoto (magnitud 8,6 grados Richter en Santiago) como el de $27 / \mathrm{F}$ es probable que cause estragos en cualquier territorio del planeta, tal escenario ha desnudado falencias de la construcción hospitalaria en Chile. Diversos actores habían trabajado en su construcción

1. En http://www.redsalud.gov.cl/minsalaudios/hospitalescampana.pdf (visitado el 10.11.2011).

2. Una clínica orientada al quintil más rico de la población cuya estructura de propiedad corresponde a una sociedad anónima, de la cual el Presidente Piñera participó hasta poco antes de asumir sus funciones.

\begin{tabular}{|c|c|c|c|}
\hline \multicolumn{4}{|c|}{ HOSPITALES DE CAMPAÑA } \\
\hline ORIGEN & CARACTERÍSTICAS & LUGAR & FECHA INSTALACIÓN \\
\hline Ejército de Chile & $\begin{array}{l}\text { Puesto Avanzado Militar de Emergencia (PAME I). } \\
\text { Cuenta con hospitalización. } 25 \text { camas. }\end{array}$ & Talca & 1 de marzo \\
\hline Ejército de Chile & $\begin{array}{l}\text { Puesto Avanzado Militar de Emergencia (PAME II). } \\
\text { Cuenta con hospitalización. } 45 \text { camas. }\end{array}$ & Curicó & 1 de marzo \\
\hline Ejército de Chile & $\begin{array}{l}\text { Puesto Avanzado Militar de Emergencia (PAME III). } \\
\text { Cuenta con hospitalización. } 25 \text { camas. }\end{array}$ & $\begin{array}{l}\text { Redestinado a } \\
\text { Cauquenes }\end{array}$ & En tránsito \\
\hline Ejército de Chile & $\begin{array}{l}\text { Puesto Avanzado Militar de Emergencia (PAME IV). } \\
\text { Cuenta con hospitalización. } 25 \text { camas. }\end{array}$ & Constitución & 4 de marzo \\
\hline Ejército de Chile & $\begin{array}{l}\text { Hospital Militar de Campaña I. Cuenta con } 1 \text { pabellón } \\
\text { (x2), } 4 \text { camillas de recuperación, laboratorio y } \\
\text { esterilización. } 20 \text { camas. }\end{array}$ & Talca & 2 de marzo \\
\hline $\mathrm{FACH}$ & $\begin{array}{l}\text { Hospital de Campaña II. Cuenta con } 1 \text { pabellón y } 15 \\
\text { camas de hospitalización. }\end{array}$ & Curanilahue & 3 de marzo \\
\hline Argentina & $\begin{array}{l}\text { Hospital Militar de Campaña III. Cuenta con } 2 \\
\text { pabellones, } 8 \text { Unidades de Pacientes Críticos (UPC) y } \\
40 \text { camas }\end{array}$ & Curicó & 7 de marzo \\
\hline Perú & $\begin{array}{l}\text { Hospital Militar de Campaña IV. Cuenta con } 2 \\
\text { pabellones, } 4 \text { UPC, } 4 \text { boxer y } 20 \text { camas. }\end{array}$ & Hualpén & 4 de marzo \\
\hline Cuba & $\begin{array}{l}\text { Hospital de Campaña V. Cuenta con } 1 \text { pabellón, } 4 \text { camas } \\
\text { críticas, Eco, laboratorio y } 20 \text { camas. }\end{array}$ & Rancagua & 4 de marzo \\
\hline Brasil & $\begin{array}{l}1 \text { Pabellón, } 2 \text { camas críticas, } 20 \text { camas. Boxes } \\
\text { ambulatorios }\end{array}$ & Félix Bulnes & 5 de marzo \\
\hline Estados Unidos & $\begin{array}{l}2 \text { pabellones, } 10 \text { camas hospitalización iniciales pueden } \\
\text { llegar a } 50 \text { o } 100 \text { camas, laboratorio, rayos. }\end{array}$ & Angol & 11 de marzo \\
\hline
\end{tabular}

Tabla 1. Distribución de Hospitales de emergencia a marzo del 2010. 
durante dos siglos para levantar la infraestructura hospitalaria chilena. ¿Quiénes han sido y que políticas los han impulsado?

\section{LA EVOLUCIÓN DE LA INFRAESTRUCTURA}

Tomemos como ejemplo los hospitales. El recientemente rescatado texto de Ignacio González Ginouvés (1) acerca de la arquitectura hospitalaria en Chile del año 1944, ${ }^{3}$ nos da algunas señas para reconstruir la situación actual. González representa algunas etapas en la historia de la construcción de hospitales, caracterizadas de acuerdo a criterios multifactoriales y heurísticos particulares. ${ }^{4}$ Tal texto tiene el mérito de reunir los antecedentes relativos al origen de las iniciativas de construcción previas a la fundación del Servicio Nacional de Salud, lo que permite observar la variopinta composición de la misma, así como juzgar los papeles jugados por el Estado y otros actores sociales privados, Iglesias, etcétera. Aparentemente, ${ }^{5}$ existe consenso en que hasta bien entrado el siglo XIX, las ideas rectoras en la construcción de hospitales han estado basadas en las necesidades estratégicobélicas y la caridad. Durante la Conquista, los hospitales -excepto el de Arica-se construyeron para enfrentar la Guerra de Arauco. Así se edificaron el "San Juan de Dios (1553); el de La Serena (1559); Osorno (1559); Cañete (1560); Concepción e Imperial (1561); Villarrica (1563) y Arica (1577)”.(op. cit., p. 352). Por otra parte, la arquitectura revela, en sus planos bidimensionales, la obra cristiana. Tienen forma de cruz y una capilla está instalada en su interior (op. cit., p. 366).

3. Publicado por esta misma revista durante el año 2012.

4. Las etapas son: hospitales de la conquista, colonia, independencia; periodos de 1870-1910, 1910-1927, 19271934 y finalmente la etapa del monoblock.

5. "Durante todo el periodo colonial, las medidas sanitarias adoptadas no lograron impactar en el estado de salud de la población: la viruela y el tifus exantemático diezmaban el país". Ernesto Miranda R. "Descentralización y privatización del sistema de salud chileno" Estudio Público, 39. Centro de Estudios Públicos, Chile, 1990, p. 9.
Durante la Colonia, la disponibilidad de profesionales era insuficiente para atender con precisión las necesidades de las personas. Se edifica, sin embargo, un buen número de hospitales para una vida al interior de las ciudades. Respecto al origen de la iniciativa de levantamiento se podría afirmar que mayoritariamente dependieron del balance entre las demandas de los colonos y la voluntad de la Corona española a través del mandato de su Virreinato.

Hacia fines del siglo XIX, la envergadura y dimensiones que el discurso médico alcanzó en Europa empujan a los países a desarrollar alianzas científico políticas que culminan con advenimiento de inmensos planes de control de la población. Surge el higienismo; es la época en que Rudolph Virchow declara que medicina es una ciencia social y que la política no es más que medicina a gran escala. Pero es también la época del control industrial. Época que deviene enbiocracias (Roudinesco) y las biopolíticas (Foucault) y asimismo de garantías estatales a la producción industrial en vistas del inmenso plan desarrollista de Occidente. En Chile, esto se traduce en el momento de los grandes médicos políticos y de las construcciones monumentales del Centenario de la República, y del gran hospital para una gran república: Hospital del Salvador, San Borja, San José, Temuco, Angol, Talca, etcétera. Hay tuberculosis y la sífilis está causando estragos. Hay un giro, a partir de "los nuevos descubrimientos de Pasteur" (op. cit., p. 348); se generan cambios "que revolucionaron la arquitectura de los hospitales"(ibídem).

En 1952 se instituye el Servicio Nacional de Salud (SNS) quedando el comando de la asistencia estatal de salud en manos del todopoderoso Director del Servicio. Este hito representa el anhelo de identificarse con un único proveedor de servicios de salud a escala nacional, cuestión enarbolada en la década del cuarenta por el entonces ministro de Salubridad del Frente Popular, durante la administración del presidente Pedro Aguirre Cerda, el Dr. Salvador Allende Gossens, ${ }^{6}$

6. Según Ricardo Cruz-Coke: "El programa médico social, se iniciaba con la reestructuración del Ministerio, reforma de los regímenes de previsión y de las leyes del 
quien redactó el proyecto de ley que originaría el SNS.

Mientras Salvador Allende está pensando el proyecto de ley que unificaba los diversos servicios de salud del país, a la inglesa, y Ricardo (Eduardo) Cruz-Coke establecía la obligatoriedad de los exámenes preventivos (1938), la modernidad en la arquitectura sanitaria (monoblock de hormigón $\operatorname{armado}^{7}$ " $f u e$ introducida entre nosotros por el Dr. Alejandro del Río" (ibídem), aunque lo hizo cien años después de introducido su uso en Europa. La atención médica se especializa de una manera nunca antes vista, gracias al advenimiento de la técnica médica moderna y los afanes analíticos que subyacen al apogeo de la técnica médica, produciendo espacios segregados. Alejandro Del Río obedece a las ideas del neohipocratismo, "un hospital activo en la lucha contra la enfermedad" (ibídem). En los primeros años del siglo XX: medicina preventiva: "se crean los consultorios pre-natales y de control de ninos sanos..." (op. cit., p. 350). Es la medicina preventiva, heredera del movimiento de higienistas de Europa. Son contemporáneos los hospitales que González Ginouvés identifica

seguro obligatorio y de medicina preventiva ampliando las coberturas. Reestructuraba la Dirección de Sanidad y reforzaba el control de drogas y medicamentos. Finalmente proponía medidas legislativas complementarias de carácter punitivo. Durante su gestión, Allende logró realizar solo parcialmente sus proyectos, pero inició el proceso de unificar las estructuras asistenciales, que llegaría a ser realidad en 1952 con la dictación de la Ley del Servicio Nacional de Salud, que consiguió su compañero de curso el Ministro Jorge Mardones”. En Síntesis biográfica del doctor Salvador Allende G. Rev. Méd. Chile, 2003; 131: 809-14.No es menor que esta cita sea del Dr. Ricardo Cruz-Coke, quien es hijo del a su vez Dr. Eduardo Cruz-Coke -el Iluminado-, autor de la Ley de Medicina Preventiva de 1938, quien fue ministro de Salubridad de Arturo Alessandri, y militante del entonces católico Partido Conservador. Además, aunque no sea gran aporte recordarlo, nuestro actual ministro de Cultura, Luciano Cruz-Coke, es su sobrino.

7. Técnica que ya se conocía desde a lo menos un siglo: "La primera idea de asociar directamente un entramado de barras de hierro con hormigón para construir bloques de construcción parece remontarse a 1820, en el transcurso del cual, una parte de la iglesia de Courbevoie, en Francia, fue cubierta por medio de planchas metálicas recubiertas por sus dos caras por una capa de mortero de cemento". Ziegler, A. Construcciones de hormigón armado. Barcelona: Juan Bruguer Editor. Barcelona, s/f, p. 7. como monoblocks. Aunque en algunos persisten simbólicamente rasgos arquitectónicos cristianos, como en el Hospital del Salvador.

Una curiosa coincidencia con la actual situación es que en 1939 habíase producido en Chile el gran terremoto de Chillán, que dejó en el suelo dicha ciudad, con la impresionante cantidad de 30 mil muertos, cuestión que debió enfrentar el ministro Allende. Este hecho está notablemente unido a tal proyecto de ley. Sin embargo, la concepción de tal modelo de asistencia sanitaria, la unificación para evitar duplicaciones de respuesta y aumentar la cobertura, demoró más de una década en cuajar (19391952), en el seno de nuestro Poder Legislativo.

Una comisión, encargada "a el abogado falangista Francisco Pinto Santa Cruz y el médico sanitarista Benjamín Viel”, (2) viajó a conocer el National Health Service, creado en 1948 en Inglaterra, como un modelo a imitar, cuestión que, no obstante lo anterior, empieza a sonar algo extraña, pues el nivel de integración social de ambas sociedades podría haber sido un a priori limitante para el emprendimiento de tal proyecto. Pero en fin, ellos viajaron, y finalmente las ideas diversas convergieron en una necesidad de organizar la Seguridad Social, dictándose la Ley 10.383 de 1952, que crea simultáneamente el Servicio de Seguro Social y el Servicio Nacional de Salud.

Carlos Molina Bustos desarrolla estas ideas exhaustivamente en su tesis de grado (3) realizando agudas observaciones acerca del origen del SNS, a la base del proyecto de Allende, pero modificado, negociado y parcelado bajo los intereses de los conservadores y radicales, representados por Eduardo "el iluminado" Cruz-Coke y Julio Bustos, respectivamente.

Ocurre que la discusión de seguros/sistemas ni estaba resuelta, ni tampoco había un consenso para justificar la existencia de una sola forma de asistencia sanitaria, precisamente porque la desintegración social lo impedía. Había que tener un sistema para ricos y otro para pobres.

El financiamiento del Seguro Social era tripartito: Estado, obrero y patrón aportaban para las prestaciones contempladas en la Ley 10.383. Así se confirma el nacimiento de un Servicio Nacional de Salud dedicado a los 
más pobres, perdiendo de inmediato su vocación de cobertura nacional total.

El primer director general de tal Sistema fue el Dr. Hernán Urzúa, siendo sus colaboradores "con los Drs. B. Juricic y Abrabam Horwitz como primer director ejecutivo $y$ regulatorio, respectivamente". 8 (4)(15) No es un hecho menor mostrar aquí que el Dr. Horwitz, posteriormente a este cargo, ocupó el de director de la Organización Panamericana de Salud durante 17 años seguidos, bajo los gobiernos de Carlos Ibáñez del Campo, que lo postuló, Jorge Alessandri Rodríguez, Eduardo Frei Montalva, Salvador Allende y la dictadura de Pinochet. ${ }^{9}$

El Servicio Nacional de Salud (SNS) así creado a imagen y semejanza del National Health Service británico creció durante casi tres décadas, desarrollándose en paralelo una notable mejoría en el nivel de salud de la población, resolviendo apremiantes temas de nutrición y mortalidad infantil, mostrando un impresionante despliegue de capacidad técnica con campañas de inmunizaciones masivas, mejora de la expectativa de vida, mortalidad materna, entre otras. Obviamente no podemos atribuir el total de esta mejora al trabajo del SNS, porque ya sabemos el valor preponderante de los determinantes sociales del nivel de salud. El propio Allende lo había enunciado en 1939 en su texto La Realidad Médico Social Chilena. Para muestra un botón: "Chile, al igual que la mayoría de los demás países sudamericanos, ha vivido a merced del coloniaje económico y cultural que ba obstaculizado el progreso social y el desarrollo de nuestras riquezas naturales. Más aún, estos factores han impedido que el pueblo logre el standard de vida compatible con el de pais civilizado y medianamente culto". (5) Esta mirada estructural histórica apuntaba a lo que

8. La cita textual en inglés es: "with Drs. B. Juricic and Abraham Horwitz as the first executive and regulatory directors, respectively".

9. Nos dice Jorge Jiménez de la Jara: “ El Gobierno de Chile postuló su mejor hombre para dirigir la OPS y en votación mayoritaria, el doctor Horwitz fue elegido su Director en 1958, siendo reelecto por periodos consecutivos de cuatro años, el último de los cuales terminó el 31 de enero de 1975” (Enrique Laval, 2006) sería más adelante la campaña presidencial de Allende; dada la escena social, las reformas sociales debían ser a una escala mayor que la que el Ministerio de Salubridad permitía.

Otro mega terremoto, el de 1960, derrumba el Hospital de Valdivia, ${ }^{10}$ que había sido ejecutado bajo está última mirada de hospital moderno, en 1939, funcionando durante décadas de manera aislada en tres recintos diferentes, hasta la década de los noventa, donde resulta normalizado bajo el gobierno de Eduardo Frei Ruiz-Tagle.(7)

La actual conformación del Sistema $\mathrm{Na}$ cional de Servicios de Salud (SNSS) es una institución que nace al alero de las reformas políticas de la dictadura, en 1979, bajo la forma del DFL 2.763, "que reorganiza el sistema de salud" pasando de una institucionalidad basada en la existencia de un Servicio Nacional de Salud, ${ }^{11}$ a un sistema mixto de aseguramiento y prestación de servicios de salud.(6)

\section{LAS FUENTES DE FINANCIAMIENTO}

Se podría mencionar que en los orígenes, la forma de construir infraestructura sanitaria del Chile colonial y republicano ha estado a cargo de una multitud de diferentes actores, a saber: Iglesias, privados autogestionados (cajas obreras), privados con fines benéficos y más tardíamente instituciones estatales.

10. "Fundado en 1939 para la atención de pacientes de las zonas de Cautín a Chiloé. Como consecuencia del terremoto que azota a la ciudad de Valdivia en el año 1960, sus dependencias resultan gravemente dañadas, por lo que tuvo que funcionar en tres recintos asistenciales ubicados en diversos sectores de la ciudad y conocidos como Hospitales Regional, Traumatológico y Kennedy”. En página web del Hospital Base de Valdivia.

http://www.hbvaldivia.cl/web/index.php?option=com content\&view=article\&id=14. (visitado 12.12.2012).

11. Valdivieso, Ramón. Juricic, Bogoslav, nos dicen en El Sistema Nacional se Salud en Chile que “...El SNS resultó de la fusión de la Sanidad, la Beneficencia con sus hospitales, el servicio médico del Seguro Obrero, la Dirección General de Protección a la Infancia, los servicios médicos de las municipalidades, la sección de accidentes del trabajo dependiente del ministerio del ramo y el Instituto Bacteriológico”, p. 479. Enhttp://hist.library.paho. org/spanish/Bol/v68n6p478.pdf (visitado el 16.9.2010). 
Efectivamente desde aquella fecha hasta 1982 funcionó la Sociedad Constructora de Establecimientos Hospitalarios S.A. (SO$\mathrm{COEH}$ ) empresa de propiedad mixta (Estado, algunos ciudadanos propietarios de acciones, Junta Central de Beneficencia y Asistencia Social), que básicamente“...estaba encargada de los aspectos financieros de las obras diseñadas en los talleres multidisciplinarios del Departamento de Arquitectura del Servicio Nacional de Salud (SNS), hasta que en 1967 la Sociedad Constructora creó su propio Departamento Técnico" (8). Dicha sociedad continuó funcionando en forma paralela al SNS hasta el año 1982. Para hacerse de un nombre, mencionaré que fue vicepresidente de esta sociedad don Arturo Matte Larraín, senador de la República por el partido liberal (1947-1957) y candidato a la Presidencia de la República, presidente de la Compañía de Aceros del Pacífico (CAP) y consejero de la Caja del Seguro Obrero, entre otros cargos.

Las preocupaciones de financiamiento por la infraestructura sanitaria estaban planteadas desde esta óptica tripartita; Estado, privados y beneficencia-caritativa. Existía la Polla Chilena de Beneficencia, una lotería de curioso nombre, muy popular y regresiva en su concepto, al transferir los costos del funcionamiento de los hospitales al pueblo consumidor de suerte, que era precisamente el público usuario de los servicios de salud. La Polla entregaba semanalmente premios millonarios, ya la vez recursos a diversas instituciones tuteladas, en un principio, por la Junta de Beneficencia.

En 1982, mediante la Ley 18.126, se disuelve la Sociedad Constructora de Establecimientos Hospitalarios y en su reemplazo le encomendó a FONASA hacerse con los bienes de la ex Sociedad, expropiando de paso a quienes poseían acciones de dicha sociedad y re-estableciendo el Departamento de Arquitectura Médica en el Ministerio de Salud, modificación del DFL2.763/79 mediante.

Los ex trabajadores de la SOCOEH fueron traspasados al Ministerio y a los Servicios de Salud de manera discrecional. Un par de años más tarde, los establecimientos asistenciales serían traspasados a los Servicios de Salud. Este mismo impulso repone en el Ministerio de Salud al Departamento de Arquitectura Médica-cuya enrevesada existencia señalamos superficialmente-. Sus funciones aparecen explicitadas en el Decreto 116 de 1982:

"Las funciones del Departamento de Arquitectura Médica serán las siguientes:

a) Estudiar, diseñar y proponer politicas y normas relacionadas con materias de diseño, proyectos, construcciones, transformaciones y reparaciones de edificios, destinados a establecimientos hospitalarios de los Servicios de Salud; b) Ejecutar, revisar $y$ aprobar todo anteproyecto y proyecto que los Servicios de Salud requieran; c) A solicitud de los Servicios de Salud, coordinar la confección de los planos de arquitectura, cálculos, instalaciones y especialidades, especificaciones técnicas y bases administrativas para llamar a propuestas; d) Controlar, supervisar e inspeccionar las obras en ejecución en los Servicios de Salud y efectuar su evaluación posterior; e) Asesorar a los Servicios de Salud en los llamados a propuesta y en la recepción de las obras que ellos deban realizar; f) Mantener estadísticas y análisis de costos de construcción, y g) Asesorar a las autoridades del Ministerio y a los Directores de los Servicios en materias de su competencia, y ejercer las demás funciones que se le encomienden respecto de estas materias".(9)

Asimismo, el Departamento de Arquitectura Médica tiene una existencia, por una parte desde 1953 a 1959 bajo dependencias del Ministerio de Salubridad; desde 1967 a 1982 en la SOCOEH y después resucita en 1982, nuevamente en el MINSAL, para nuevamente desaparecer el año 2005.

Sin embargo durante la administración del presidente Ricardo Lagos Escobar, mediante el Decreto 136, artículo 16, se especifica la nueva incumbencia ministerial, redefiniendo el rol del Estado en asuntos de provisión de servicios asistenciales: “...Es función del Ministerio de Salud establecer los estándares minimos que deberán cumplir los prestadores institucionales de salud, autorizados sanitariamente para funcionar, tales como hospitales, clinicas, consultorios y centros médicos, con el objeto de 
garantizar que las prestaciones alcancen la calidad requerida para la seguridad de los usuarios".(10); firma como ministro de Salud el Dr. Pedro García. ${ }^{12}$ Es decir, el Estado en un rol garantista de estándares mínimos en salud.

Acorde con una mirada liberal imperante en el mundo de manera globalizante, Lagos Escobar entiende rápidamente que las reformas de los servicios sociales deben apuntar al eje rector-regulación antes que provisión y financiamiento, y así -con amplios consensos de los sectores políticos representados en el Poder Legislativo- el Estado pasa a ser el encargado de regir y regular el mercado de prestaciones en salud, centrando su atención en la fiscalización del cumplimiento de las normas. Cabe decir que es en esa administración donde se elevan las primeras propuestas de construcción de hospitales mediante el mecanismo de financiamiento conocido como Concesión, para los hospitales de Maipú y La Florida. Como se sabe, la concesión permite en Chile al agente privado invertir en alguna actividad económica de público interés, como autopistas, aeropuertos, puentes y hospitales, y el Estado le garantiza el usufructo de dichas instalaciones -como una forma de retribuir la inversión y asegurar el rédito (y lucro) al inversionista-, al tiempo que satisface una necesidad poblacional por una vía rápida, mas no necesariamente eficaz ni eficiente.

Hay un claro viraje entonces, desde la antigua, y quizás nunca implementada totalmente, concepción en la que el Estado se debe hacer cargo de la provisión de servicios sociales organizados en salud, a la mirada actual en la que el Estado solamente regula y externaliza servicios que no pueden ser entregados con iguales condiciones -la buena fe lo supone- que los privados.

Así podemos entender la actual política del Ministerio de Salud de Jaime Mañalich, médico independiente, ${ }^{13}$ actual regente del Ministerio de Salud. Él ha continuado con la

12. Estas disposiciones pierden vigencia el año 2005, al derogarse el decreto supremo 395, al que hacía alusión al referido Decreto 116.

13. Mañalich ha declarado pertenecer al "partido de los enfermos". política de las concesiones que habían iniciado los gobiernos anteriores, apoyando a los proyectos de concesiones de Maipú y La Florida, que ya habían sido adjudicados durante el último gobierno de la Concertación. ${ }^{14}$

Tales proyectos oficialmente fueron presentados al país en el Mensaje Presidencial de Michelle Bachelet el 21 de mayo de 2006, iniciándose los estudios durante la administración de la ministra Dra. María Soledad Barría, en 2007-con quién trabajé en dicho Ministerio-. Se anunció su construcción para el año 2012 y su puesta en funcionamiento el año 2013. Actualmente se encuentran aún en etapa preoperatoria, habiéndose anunciado que entraría en funcionamiento, en cuanto a prestaciones ambulatorias se refiere, a partir del 15.11.13 en el caso de Maipú y Cerrillos (http://goo.gl/Vwv3QW). La gran diferencia que marcará con el resto de los hospitales de la red estatal es que precisamente su construcción se financiará con la concesión de la operación no clínica (lavandería, cocina, laboratorio, estacionamientos, aseo, farmacia, etc.), todos servicios que estarán sujetos a contratos de trabajo con las entidades privadas que administrarán estos hospitales.

A la hora de administrarlos, han quedado en manos diversas, dependiendo fundamentalmente del origen histórico de su construcción. La administración quedaba en manos de sus dueños o creadores, según se guste.

Los médicos quedan - por ahora- fuera de esta nueva forma de gobernar los hospitales, por diversas razones que incluyen una buena negociación con la autoridad al hacer ver lo inconveniente de tal suceso:

...el ministro Álvaro Erazo destacó que

"sacamos lecciones de las cosas que no hay

14. “Adjudícase el contrato de concesión para el diseño, construcción, reparación, conservación, mantención, operación y explotación de la obra pública fiscal denominada "Programa de Concesiones de Infraestructura Hospitalaria”, conformado por el Hospital de Maipú y el Hospital de La Florida, ubicados en la Región Metropolitana de Santiago, a las empresas "Constructora San José S.A.” y “Tecnocontrol S.A.”” (MINSAL, Decreto 230/2009). Este grupo es un gran Holding de inversiones en el sector de la construcción de origen español, con amplios intereses en la región. 
que hacer y estamos transfiriendo la gestión operacional, fundamentalmente los servicios básicos, pero no los servicios clinicos, para que acá de verdad tengamos un hospital de primer nivel.(11)

Por su parte Mañalich ha reforzado lo dicho por Erazo, señalando que "La concesión no incluirá a aquellos funcionarios públicos que tengan una relación directa con el paciente, vale decir, el camillero que los trasporta, el que lo asea, el técnico paramédico, entre otros..."(12). Esta es una clara batalla ganada por el gremio médico, que ve así resuelta la ansiedad que les generaba la adquisición de un nuevo patrón privado, con sus reglas e intereses que podrían perjudicarles.

Mañalich deberá mantener su postura pese a Libertad y Desarrollo, el tanque pensante o think tank vinculado al gremialismo de la Unión Demócrata Independiente (UDI) -el otro partido de gobierno-, que en un documento denominado "Diagnóstico y Remedios para la Crisis Hospitalaria” señalan claramente su postura: "Los hospitales deberian convertirse en sociedades anónimas hospitalarias y competir entre si y con otras organizaciones privadas por convenir las atenciones de la población suscrita en los seguros públicos o privados de salud".(13)

\section{PORTABILIDAD Y LIBRE ELECCIÓN}

Otro tema discutido de acuerdo a la agenda del cambio es la portabilidad de los subsidios estatales, es decir, entregar a las personas la decisión de escoger el prestador que más y mejor le parezca, de manera de aumentar la competencia por los pacientes entre los diversos actores públicos y privados que ofrecen servicios. En este tema en particular no se ve mayor disidencia. Desde el gobierno, Mikel Uriarte, director del Fondo Nacional de Salud (FONASA) y concejal por la comuna de Las Condes, ha señalado que: "Existirá una portabilidad del bono para que la persona vaya al recinto que tenga las mejores condiciones, pero confiamos en que el esfuerzo de los servicios públicos será capaz de absorber la demanda”.(14)
Sin embargo, es preciso señalar que la modalidad de financiamiento así descrita o subsidio a la demanda, como se conoce en jerga experta, ya existe en el repertorio de prestaciones del FONASA, bajo el nombre de "modalidad de libre elección”, que no es más que un subsidio estatal a la demanda por atención médica de la ciudadanía, con un copago asociado.

Asimismo, desde el centro de estudios Salud y Futuro, vinculado a la Universidad Andrés Bello y a salubristas democratacristianos, por nombrar a algunos opositores políticos del actual gobierno, también ven con cierto afecto la portabilidad, pues le entregaría eficiencia al sistema, como una totalidad.

\section{A MODO DE CONCLUSIÓN: TÉCNICA Y DETERMINANTES SOCIALES}

Curiosamente, el año 1944, se consolida la lógica de un financiamiento mixto estatalprivado, que nos acompaña hasta el momento, de una forma u otra. Esto, probablemente ocultó de manera profunda y eficaz una realidad devastada por la pobreza, la inequidad y en definitiva la organización de la sociedad como el principal determinante del nivel de salud de la comunidad. Efectivamente, la pobreza se evidenció en la muerte, el derrumbe de las estructuras agitadas por la tierra, pero también por el devenir histórico en rural pobre, marginado, carente de infraestructura social y en definitiva de una profunda inequidad que revela una sociedad desintegrada.

Falta de integración que se coronó con la voz y manos de la caridad, esa vieja y conoci$\mathrm{da}$ asistencia a la gente que sufre, internacional clamor que hermanó las ciudades chilenas afectadas por el seísmo, Talca, Constitución, Concepción y sus balnearios, entre las más dañadas, con la localidad italiana de L'Aquila, devastada por su propio remezón en el año 2011, caridad enemistada con el pragmatismo material e histórico, que hizo a las nuevas autoridades rechazar tempranamente la permanencia de la tienda rusa ${ }^{15}$ caridad que en fin, nos hermana,

15. Un confuso diagnóstico de nuestras autoridades llevó a instalar el hospital ruso al costado de un gran hospital 
hospedaje mediante, con una de las peores de todas las caras de la modernidad. ${ }^{16}$

Asimismo, después de los terremotos o revoluciones tectónicas, las debilidades de la infraestructura hospitalario-asistencial chilena, rápidamente quedó afectada, de manera tal que su caída vino a componer un especial tinglado muy favorable a desarrollar cambios, justo en un momento en que el cambio se apoderaba de la administración del Estado. ${ }^{17}$

Independientemente de los hechos aquí sucintamente expuestos, queda en los textos y subtextos de la jerga política, una suerte de traición $n^{18}$ técnica multidimensional al objetivo sanitario de elevar el nivel de salud de la comunidad.(16)

Me refiero a la forma de hacer políticas de salud, a la preponderancia delos hechos políticos por sobre la contundente evidencia sanitaria, a la falta de Integración social y a la puesta en escena del lucro en la respuesta social organizada en salud.

de alta complejidad. A los 15 días de funcionamiento, el ministro de Salud, Jaime Mañalich,declaró a la televisión "Hemos evaluado en conjunto con ellos que ya no es necesaria su presencia al lado del Sótero del Río”. Por su parte el jefe de la misión rusa, Salavat Mingaleev, dijo:"Nos vamos porque es una decisión a nivel ministerial. Nosotros tenemos que acatar las órdenes" (El Mercurio, 21.03.2010).

16. En la ciudad de París, 1656, se dicta el decreto de fundación de Hospital General, que organiza los servicios hospitalarios para la atención de todo ciudadano pobre y entrega jurisdicción a su director para que ordene su buen funcionamiento, tanto dentro como fuera del recinto. Se estableció el Hospital, como la institución social encargada de responsabilizarse por la suerte de vagos, enfermos errantes y pobres. De ahí que no deje de tener importancia el alcance etiológico histórico de las palabras hospital, hospedaje y hotel, para el mundo occidental. Además, se puede decir que todas brindan cama y techo a diversos tipos de extranjeros. Para profundizar, véase Michel Foucault, 1961.

17. Viva el Cambio fue la consigna de campaña del actual presidente Sebastián Piñera Echenique.

18. Aquí hay que sintonizar con la crítica que Martin Heidegger hace en la pregunta por la técnica, cuestión que no viene al caso reseñar demasiado, pero sí decir que la esencia de la técnica permanece desconocida, hasta que sea poyética y "trae a lo verdadero el brillo de lo que Platón llama en el Fedro..., lo que más puramente resplandece" (Heiddeger, 2002).
La renuncia del Estado a hacerse cargo de las prestaciones asistenciales integradas; esto es financiar, diseñar, construir, administrar y evaluar establecimientos asistenciales, con la supresión del Departamento de Arquitectura del Ministerio de Salud, es una primera señal de la voluntad de entregar poder del Estado nacional que caracteriza a nuestros tiempos. Por ahora nos encontramos en un limbo donde coexistirán ambos modelos por un tiempo. Los resultados de los hospitales concesionados mostrarán sus fortalezas y debilidades.

El incidente con la misión rusa, que se retiró del país por falta de pacientes, también es síntoma de aquello. Si hubiese prevalecido un criterio sanitario pragmático, se les hubiese encomendado la misión de instalarse más cerca del epicentro del sismo y no al costado de un centro de gran complejidad que resultó sin daños mayores.

Asimismo, el involucramiento de actores privados y el controvertido lucro en la escena de prestación asistencial es un notable hecho desde al menos 1944 en adelante, pues la SOCOEH ya contaba con accionistas particulares. Está en el genoma de la actividad sanitaria aquí examinada, la invitación a sectores inversionistas a participar.

Otro hecho no menos extraño, por lo revelador y aparentemente inadvertido, es la continuidad entre las principales políticas de salud de los gobiernos de la Concertación (socialdemócratas, por calificarlos de alguna manera menos localista) y la alianza liberalgremialista. A pesar del cambio de administración, se mantiene la política. ${ }^{19}$

Básicamente dichas leyes permiten la incorporación de actores privados en los ámbitos públicos donde resulten más eficientes que el Estado ejecute directamente. El usufructo de la concesión, les asegura un retorno de la inversión con creces generoso, y por supuesto, permitirá incentivar a los funcionarios a

19. En efecto, la nueva Ley de Concesiones fue elaborada en 1991, bajo el gobierno de Eduardo Frei Ruiz-Tagle, modificando el, DS294/85, del Ministerio de Obras Públicas, diseñado bajo el gobierno de Pinochet. Las últimas modificaciones son de enero de 2010, hacia el final del gobierno de Michelle Bachelet. 
cumplir sus cometidos con la lógica del mundo privado, es decir, pago por resultados.

Esto a su vez resulta incómodo y es en sí un hecho novedoso en el escenario de la salud pública chilena. Habría aquí que responder ciertas preguntas, pero eso es motivo de otro nivel de análisis. En cualquier caso las planteo: ¿Cómo se comportará el privado en la provisión de dichos servicios? ¿Qué incentivos tendrá para no reducir costos al límite de la calidad de la atención? ¿Qué herramientas tendrá el Estado para fiscalizar? ¿Cómo se comportarán los médicos en el nuevo escenario?

Finalmente, ¿cómo haber desconocido la falta de integración social que existe en la sociedad chilena, donde tenemos el $17 \%$ de la población con seguros privados de salud (Instituciones de Salud Previsional, ISAPRE), que es la población con mejor capacidad de pago, mientras cerca del $80 \%$ restante está bajo la protección del Estado? ¿Cómo se puede diseñar una política desconociendo este hecho? ¿Dónde radica la responsabilidad política?

En definitiva, parece ser que toda la legislación que se esfuerza por hacer eficiente la red hospitalaria del SNSS está ajena, no puede experimentar la realidad y por eso la lejanía de hallar un perfecto nivel de salud, entendido holísticamente, desde la mera regulación legal, sin considerar la Política.

Tras la jerga, la discusión y los intereses, aquí sucintamente expuestos, se esconde aún la realidad chilena, el nivel de salud de los habitantes de este país dista mucho de depender fundamentalmente del tipo de mecanismo de financiamiento de los hospitales o de la forma en que se subsidiará la atención médica, que es la cuestión que ha ocupado la discusión durante la mayor parte del siglo XX.

\section{REFERENCIAS}

1. González I. La Evolución de la arquitectura hospitalaria en Chile. Revista de Asistencia Social. Publicaciones de Divulgación de la Asociación Chilena de Asistencia Social. Folleto 131. 1944.

2. Labra ME. Medicina Social en Chile: Propuestas y Debates (1920-1950). Cuad Méd Soc. 2004; 44(4): 207-219.
3. Molina C. Institucionalidad sanitaria chilena 1889-1989. Santiago: LOM. 2010.

4. Mardones-Restat F, de Azevedo AC. The essential health reform in Chile; a reflection on the 1952 process. Salud Pública de México. 2006; 48(6): 504-11.

5. Allende S. La realidad médico social chilena. Chile: Ministerio de Salubridad. 1939.

6. Valdivieso R, Juricic B. El sistema nacional de salud en Chile. Bol. Oficina Sanit Panam [internet]. 1970 [consultado 16.10.2010]; 68(6): 478-485. Disponible en: http://hist.library.paho.org/spanish/Bol/v68n6p478.pdf

7. Hospital Base de Valdivia [internet]. 2010 [consultado 12.12.2012]. Disponible en: http://www.hbvaldivia.cl/web/index.php?option $=\mathrm{com}_{-}$ content\&view=article\&id=14.

8. Galeno C. Concepción sanitaria de la arquitectura: La salubridad que marcó el espacio moderno. Revista CA. 2006; 125: 36-37.

9. Chile. Ministerio de Salud. Decreto No 116. Fija establecimientos rurales de desempeño difícil de atención primaria de salud, periodo 2008 a 2012. Diario Oficial; 9.08.2008.

10. Chile. Ministerio de Salud. Decreto No 136. Reglamento orgánico del Ministerio de Salud. Diario Oficial [consultado 21.04.2005].

11. Comunicaciones de MINSAL. Ministerio de Salud recibe terrenos para construcción de Hospital de Maipú [internet]. Colegio Médico de Chile; [consultado 5.01.2010]. Disponible en: http://www.colegiomedico.cl/Default.aspx?tabid $=760 \&$ selectmod uleid $=2494 \&$ Article $I D=329 \&$ reftab $=64 \&$ title=Ministerio_de_Salud_recibe_terrenos_para_construcci\%C3\%B3n_de_hospital_de_Maip\%C3\%BA

12. Diario Estrategia. Concesión de hospitales no interferirá en gestión clínica. Domingo 25.08.2010.

13. Diagnóstico y remedios para la crisis hospitalaria [Temas Públicos]. Revista Libertad y Desarrollo. 2008; 191: 2-8.

14. Diario El Mercurio de Antofagasta. 2 años para terminar con listas de espera. Sabado 24.07.2010.

15. Laval E. Abraham Horwitz Barak. Rev chil infectol. 2006; 23(2): 106-108.

16. Heiddeger M. Filosofía, Ciencia y Técnica. $4^{a}$ edición. Santiago: Editorial Universitaria. 2003. 